San Jose State University

SJSU ScholarWorks

Master's Projects

Master's Theses and Graduate Research

Fall 2013

\title{
Pattern Recognition of DNA Sequences using Automata with application to Species Distinction
}

Parnika P. Achrekar

San Jose State University

Follow this and additional works at: https://scholarworks.sjsu.edu/etd_projects

Part of the Computer Sciences Commons

\section{Recommended Citation}

Achrekar, Parnika P., "Pattern Recognition of DNA Sequences using Automata with application to Species Distinction" (2013). Master's Projects. 334.

DOI: https://doi.org/10.31979/etd.4ysq-wbmt

https://scholarworks.sjsu.edu/etd_projects/334

This Master's Project is brought to you for free and open access by the Master's Theses and Graduate Research at SJSU ScholarWorks. It has been accepted for inclusion in Master's Projects by an authorized administrator of SJSU ScholarWorks. For more information, please contact scholarworks@sjsu.edu. 


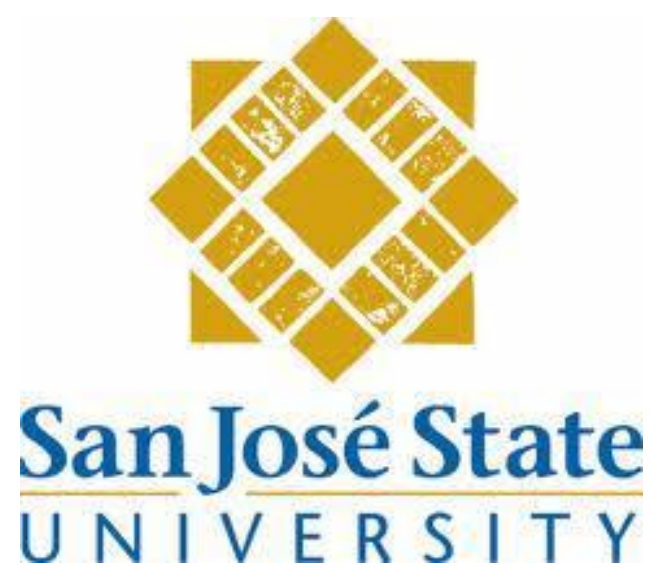

\title{
Pattern Recognition of DNA Sequences using Automata with application to Species Distinction
}

\author{
A Thesis \\ Presented to \\ The Faculty of the Department of Computer Science \\ San José State University \\ In Partial Fulfillment \\ Of the Requirements for the Degree \\ Master of Science \\ By \\ Parnika P Achrekar \\ December 2013
}


(C) 2013

Parnika P Achrekar

\section{ALL RIGHTS RESERVED}




\section{SAN JOSE STATE UNIVERSITY}

The Designated Thesis Committee Approves the Thesis Titled

\section{Pattern Recognition of DNA Sequences using Automata with emphasis on Species Distinction By \\ Parnika P Achrekar}

APPROVED FOR THE DEPARTMENT OF COMPUTER SCIENCE

SAN JOSÉ STATE UNIVERSITY

December 2013

Dr. T. Y. Lin, Department of Computer Science

Date

Dr. Chris Tseng, Department of Computer Science

Date

Mr. Amit Sant, Software Engineer at Apple Inc

Date 


\begin{abstract}
"Darwin wasn't just provocative in saying that we descend from the apes-he didn't go far enough, we are apes in every way, from our long arms and tailless bodies to our habits and temperament." said Frans de Waal, a primate scientist at Emory University in Atlanta, Georgia. 1.3 million Species have been named and analyzed by scientists. This project focuses on capturing various nucleotide sequences of various species and determining the similarity and differences between them. Finite state automata have been used to accomplish this. The automata for a DNA genome is created using Alergia algorithm and is used as the foundation for comparing it to the other species DNA sequences.
\end{abstract}




\section{ACKNOWLEDGEMENTS}

I would like to take this opportunity to thank each and every person who has contributed towards the completion of this project. Working on this project was an exciting experience. Knowledge and experience gained from this project will remain with me as an ingratiating memory.

I would like to express my special thanks of gratitude to my project advisor Dr. T. Y. Lin who gave me this golden opportunity to this wonderful project. His guidance and cooperation have helped me in completing this project successfully. Thanks for the benevolent support and kind attention. I would also like to thank my committee members Dr. Tseng and Mr. Amit Sant for their support and patience.

I would also like to thank our department for providing us with the necessary software required in our project. I'm also thankful to the library for providing necessary books and materials required to learn different concepts for our project.

Last but not the least, sincere thanks to my parents for inspiration and blessings, to my brother's constant moral support and encouragement without which project completion would have been next to impossible. I would also like to take this opportunity to thank my friends Mona, Mini, Krupali and Nikhil for being there for whenever I needed them. 


\section{$\underline{\text { Table of contents }}$}

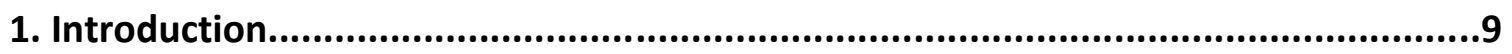

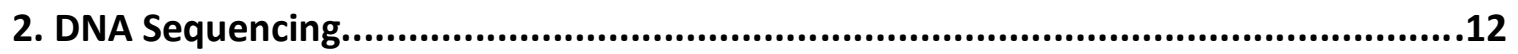

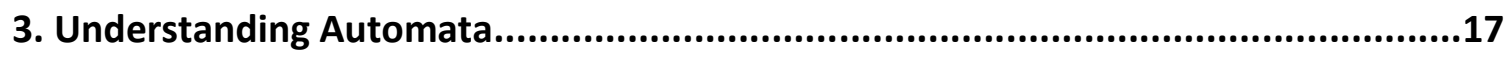

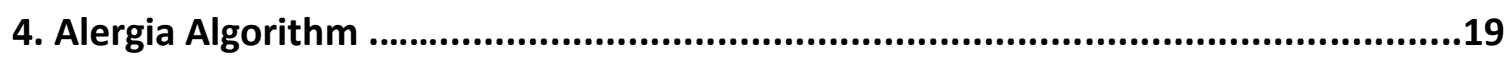

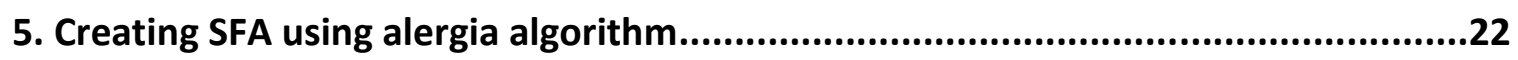

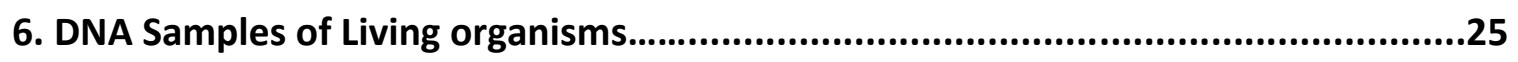

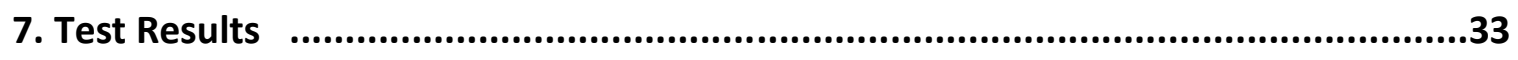

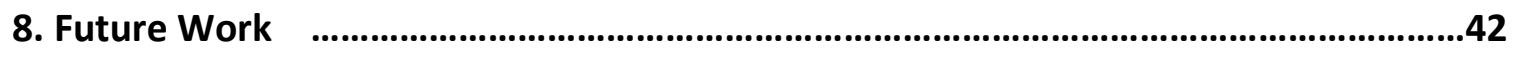

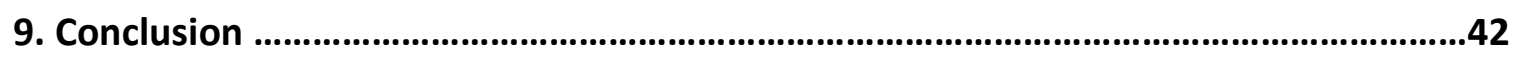

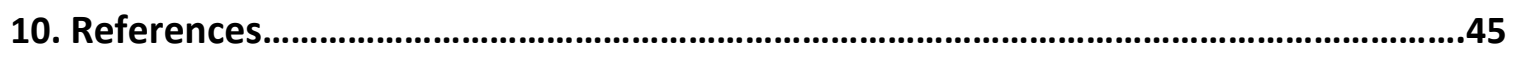




\section{List of Tables}

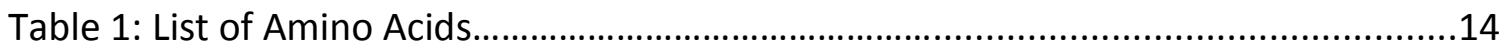

Table 2: Comparison of Human, Chimpanzee and Banana DNA …...................................33

Table 3: Comparison of Human, Chimpanzee and Mouse DNA.........................................34

Table 4: Comparison of Human, Monkey and Fruit Fly DNA ..........................................35

Table 5: Comparison of Human, Dog and E. coli DNA ….................................................36

Table 6: Comparison of Human, Mouse and Yeast DNA .................................................37

Table 7: Comparison of Human, Mouse and Yeast DNA ….................................................38

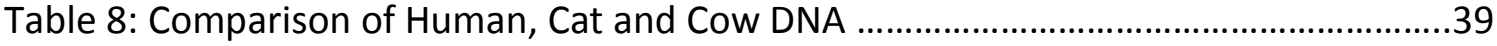

Table 9: Comparison of Human, Dog and Mushroom DNA ….............................................40

Table 10: Comparison of Human, Dog and Rice DNA ….................................................41

Table 11: Comparison of Human, Cow and E. Coli DNA ..................................................42

Table 12: Homologous Gene Summary Chart ..............................................................43 


\section{List of Figures}

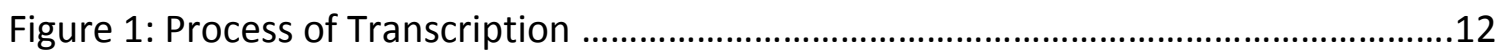

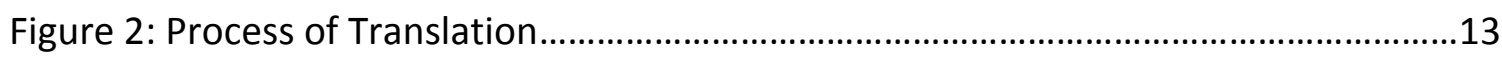

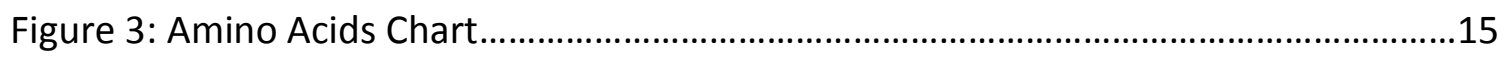

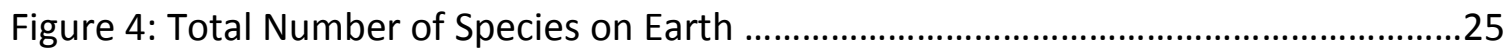

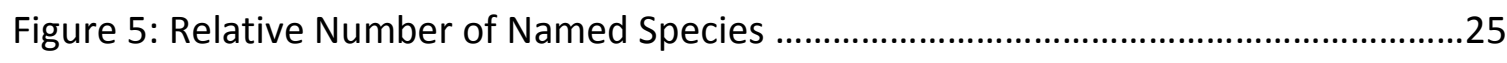

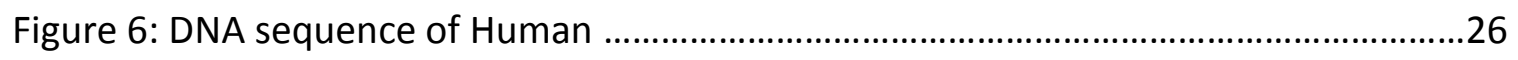

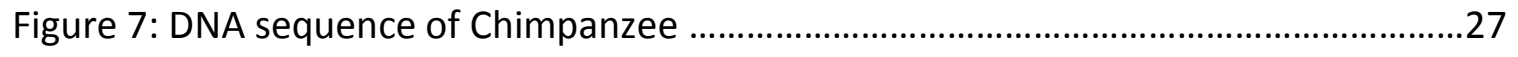

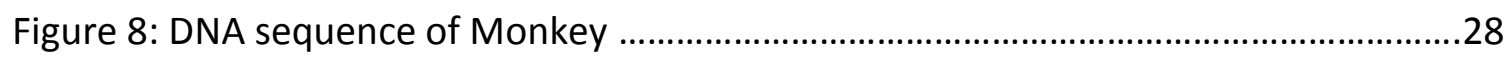

Figure 9: DNA sequence of Mus Musculus (House Mouse) .............................................28

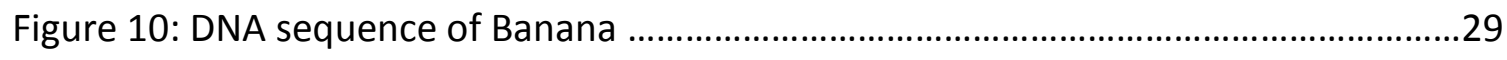

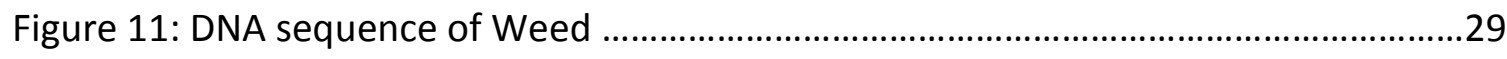

Figure 12: DNA sequence of Drosophila Melanogaster ..................................................30

Figure 13: DNA sequence of Oryza sativa (Rice) …........................................................

Figure 14: DNA sequence of Agaricus bisporus(Mushroom) …......................................32

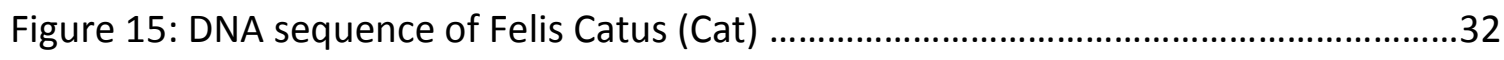




\section{Introduction}

DNA, or deoxyribonucleic acid, is the hereditary material in humans and almost all other organisms. Almost all the cells in a human body have the same DNA. Most DNA is found in the cell nucleus (where it is called nuclear DNA) however a small amount of DNA can also be discovered in the mitochondria (where it is called mitochondrial DNA or mtDNA). DNA molecules are double-stranded helices, consisting of two long biopolymers made of simpler units called nucleotides. DNA nucleobase contains 4 chemical bases: Adenine (A), Guanine (G), Cytosine (C) and Thymine (T) [15].

RNA or ribonucleic acid is an important molecule with long chains of nucleotides. A RNA nucleotide contains a nitrogenous base, a ribose sugar, and a phosphate [15]. RNA, just like DNA, is equally important for living beings. RNA is usually single stranded unlike DNA which is double stranded. RNA nucleobase is made up of 4 chemical bases: Adenine (A), Guanine (G), Cytosine (C) and Uracil (U) [2].

DNA chemical bases pair up with each other, A with T and $C$ with $G$, forming units called base pairs. A sugar molecule and a phosphate molecule are attached to each base. DNA in humans contains around 3 billion bases and these are similar in two people for about $99 \%$ of the total bases. These bases are sequenced differently for different information that needs to be transmitted [15]. This is similar to the way that different sequences of letters form words and sequences of words form sentences. 
The study of abstract machines and the computational difficulties that can be resolved using these abstract machines is called automata. Automata theory is closely related to formal language theory, as the automata are often classified by the class of formal languages they are able to recognize. A finite representation of a formal language that may be an infinite set can be automata [1].

Automata theory has been used to analyze the pattern of text data to find the writer and find the similarity and differences between him and others [5]. In biology, automata theory has been of vital importance. DNA nucleotide genomes have been symbolized using Cellular automata [13]. Hence, the study of DNA nucleobase pairs can be achieved using the automata theory.

A human DNA has approximately three billion base pairs. Searching a single gene from these vast base pairs that contribute to the human genome is known as DNA sequencing. In late 1970's, primary technique for DNA sequencing was established however scientist could sequence very few base pairs.

An enormous volume of information can be captured from one million bases or more. Matching the dissimilarity between the vast DNA sequences can help in understanding evolution, adaptation and immunity. The Human Genome Project (HGP) was dedicated to evolving innovative and improved tools to obtain gene economically, more rapidly 
and practical for scientists to achieve. Its popular sequencing of the human genome has provided scientists with a fundamental design of the human being [12].

In this project, we will create the automata of the DNA nucleotide sequence by appropriately representing the base pair sequences in the form of numerical symbols. We will further create a PTA (Prefix Tree Acceptor) to compare the sequence with various other species. 


\section{DNA Sequencing}

A segment of DNA that is transferred from parents to children is known as gene. They are systematized and wrapped in components called chromosomes. Humans have 23 pairs of chromosomes which makes them different from other creatures. A gene also codes for a single protein molecule also known as polypeptide which is also used for protein synthesis. It comprises of two steps: Transcription and Translation [9].

Transcription: The sequence of one gene is replicated in an RNA molecule [15].

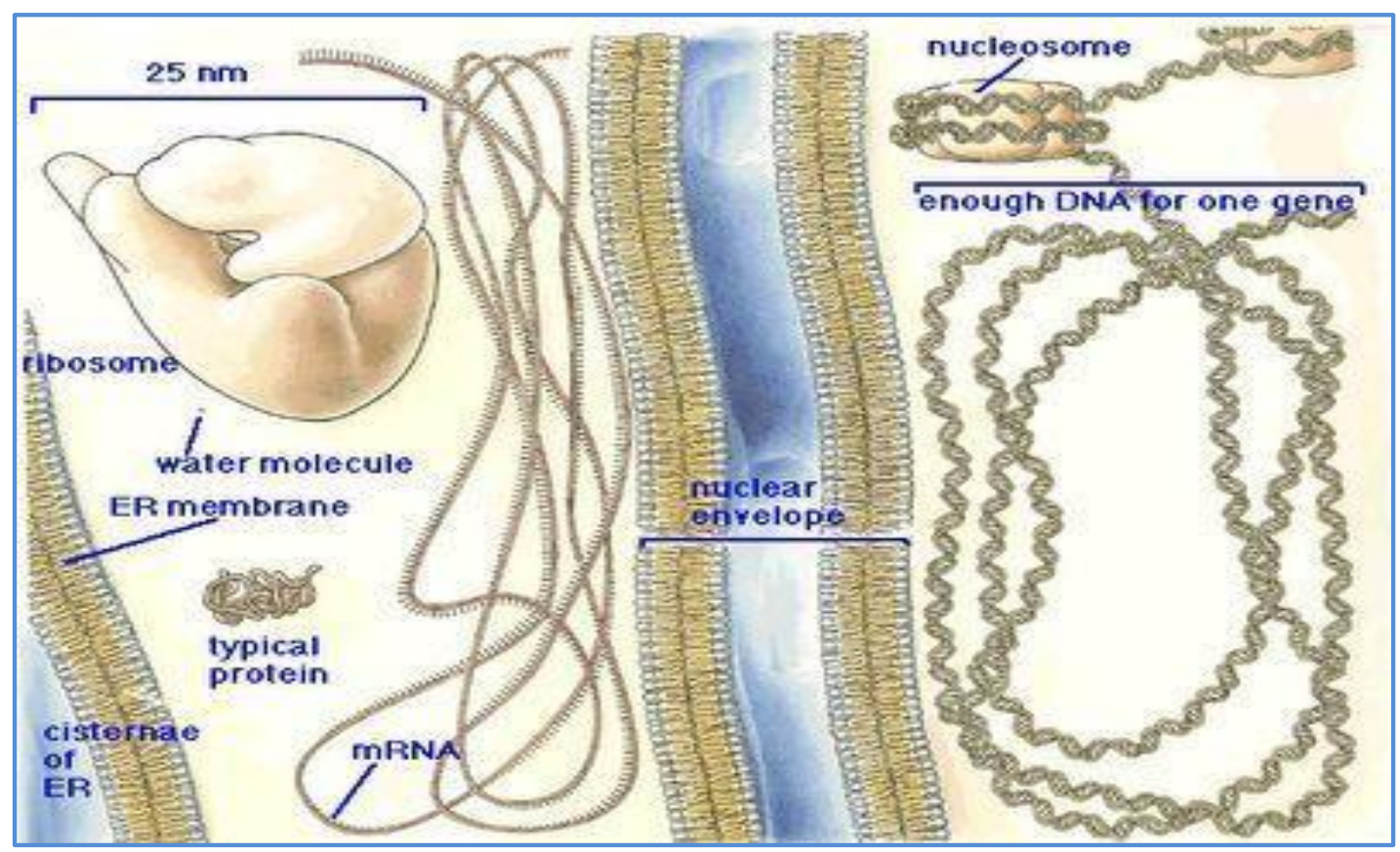

Figure 1: Process of Transcription [17] 
Translation: The RNA molecule acts as a cypher for the formation of an amino-acid chain (a polypeptide) [15].

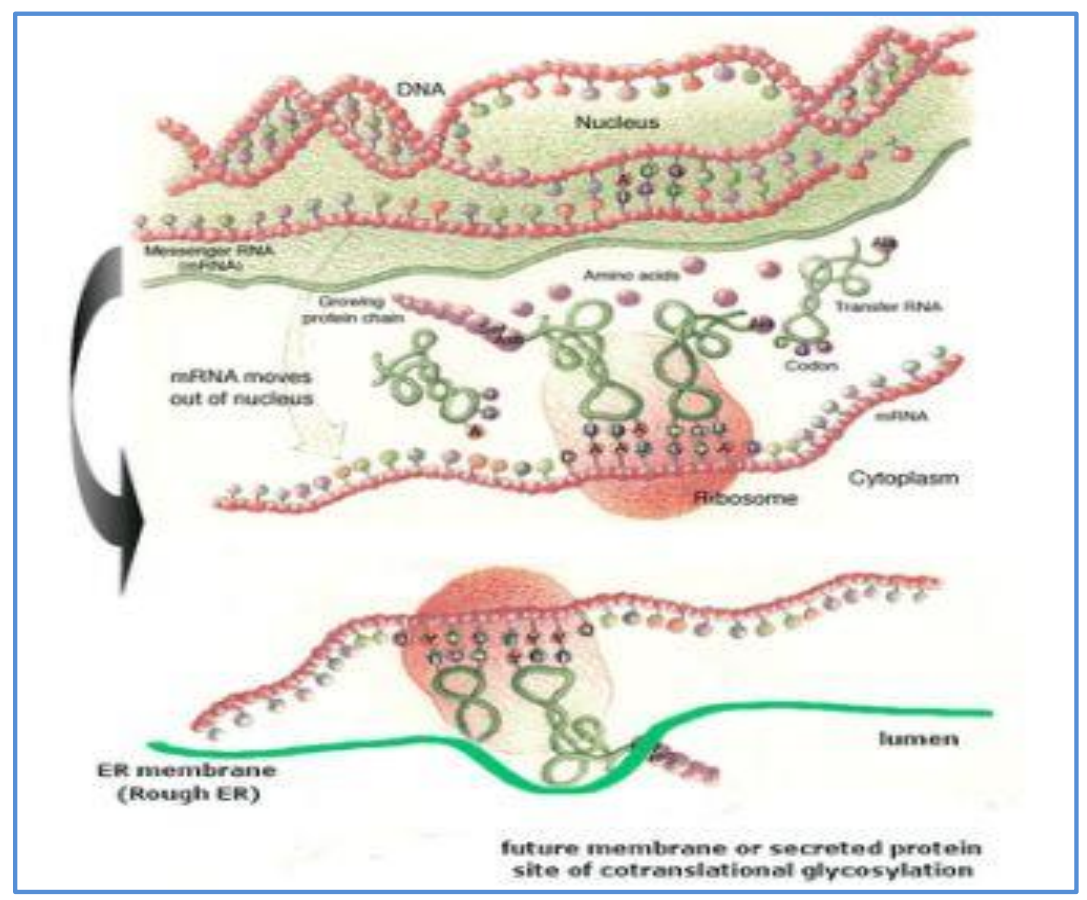

Figure 2: Process of Translation [17]

Translation of DNA to RNA into a sequence of amino acids marks the beginning of protein synthesis [9][15]. The main structure of protein is a thorough sequence of amino acids in a polypeptide string. A set of 20 naturally occurring amino acids exists today. Asparagine was discovered in 1806 followed by Cysteine, Leucine and Glucine [9]. 
Types of Amino Acids:

\begin{tabular}{|l|l|l|}
\hline Amino Acid & one letter code & three letter code \\
\hline L-alanine & A & Ala \\
\hline L-arginine & R & Arg \\
\hline L-asparagine & N & Asn \\
\hline L-aspartic acid & D & Asp \\
\hline L-cysteine & C & Cys \\
\hline L-glutamine & Q & Gln \\
\hline L-glutamic acid & E & Glu \\
\hline glycine & G & Gly \\
\hline L-histidine & H & His \\
\hline L-isoleucine. & I & Ile \\
\hline L-leucine & L & Leu \\
\hline L-lysine & K & Lys \\
\hline L-methionine & M & Met \\
\hline L-phenylalanine & F & Phe \\
\hline L-proline & P & Pro \\
\hline L-serine & S & Ser \\
\hline L-threonine & T & Thr \\
\hline L-tryptophan & W & Trp \\
\hline L-tyrosine & V & Val \\
\hline L-valine & Tar & \\
\hline
\end{tabular}

Table 1: List of Amino acids [2] 
Amino acids are categorized into four major sets based on the properties of the "R" group in each amino acid. The types of amino acids are namely polar, nonpolar, positively charged, or negatively charged [9]. Polar amino acids have "R" groups that are hydrophilic, which hunt for contact with aqueous solutions. Nonpolar amino acids are the opposite of hydrophilic; they avoid contact with liquid [10].

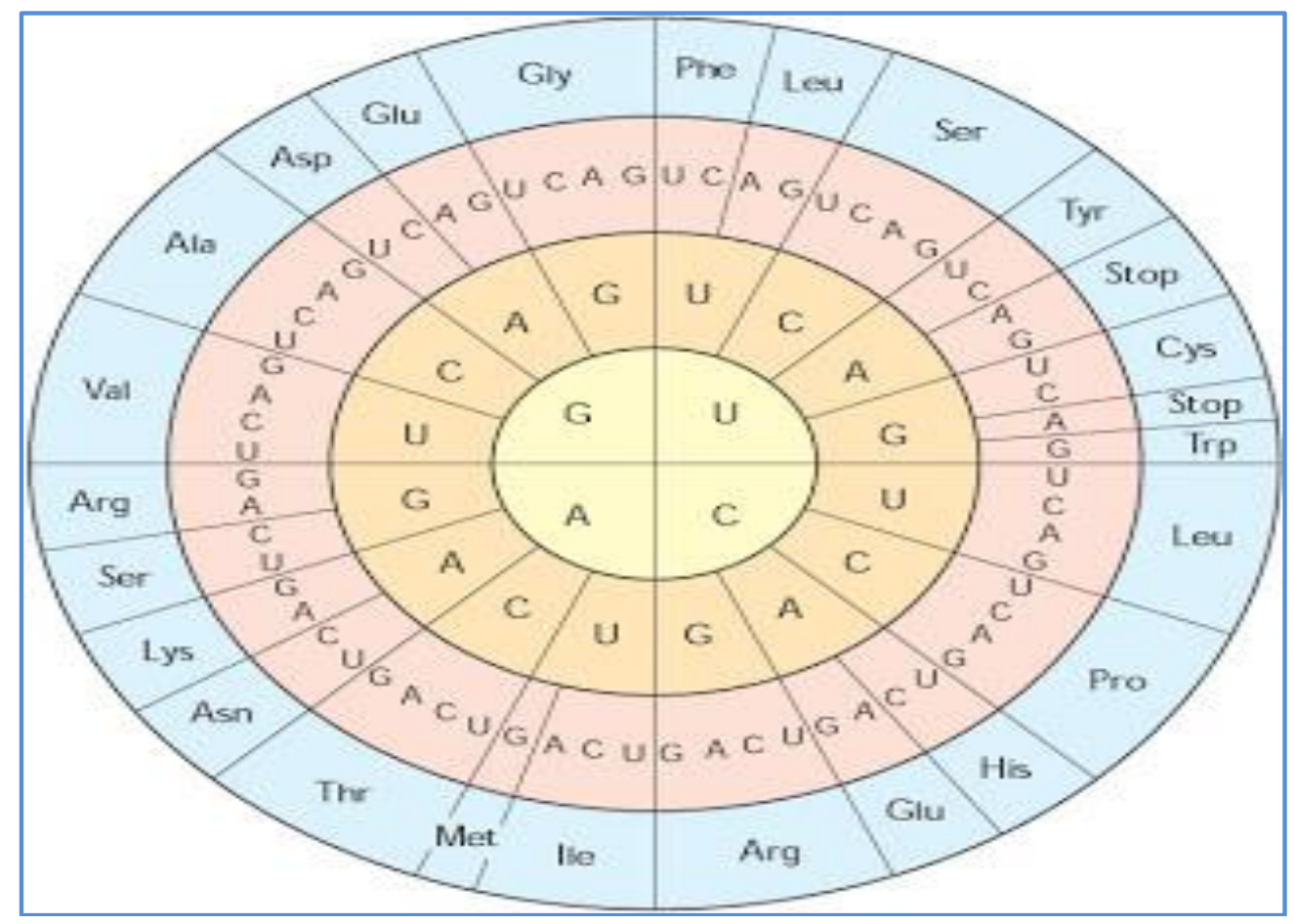

Figure 3: Amino Acids Chart [2]

There are 8 different types of essential amino acids: isoleucine, leucine, lysine, methionine, phenylalanine, threonine, tryptophan and valine. The remaining 12 are non-essential amino acids [10]. Essential amino acids perform various functions in your body including supervising insulin and maintaining healthy hair, skin, and nails. 
They act as the elementary building blocks of the human body. Deficiency in amino acids can lead to lower energy levels. It could also slower the rate of metabolism and cause skin and hair loss, indigestion, insomnia, stress etc. Obesity can be avoided by getting all the required amino acid, which in turn can help in throwing waste away from the bloodstream. 


\section{Understanding Automata}

In this section, we will understand the use of Finite Automata for representing DNA genomes [1] [3].

3.1. Finite automaton ' $A$ ' is defined as follows:

$$
A=(S, P, i, \delta, T) \text {, where }
$$

$\mathrm{S}$ : is a finite set known as set of states

P: finite input alphabet

$$
P=\{A, C, G, T\} \text { or }\{A, C, G, U\}
$$

$>$ i: fixed element of A called as initial state

$\delta:$ is a function:

$$
\delta: S \times A \rightarrow S
$$

It is known as the transition function.

$\mathrm{T}$ : is a subset of $\mathrm{S}$ known as terminal state.

\subsection{Non-Deterministic Finite Automata:}

Non-deterministic finite automata can be in various states at a single instance of time [14]. Transition from one state on an input can be to any set of states. 


\section{DFA vs NFA [14]}

\begin{tabular}{|l|l|}
\hline Deterministic Finite Automata & Non Deterministic Finite Automata \\
\hline Characterized as a 5 tuple state: $\left.\mathrm{A}, \mathrm{T}, \mathrm{S}_{0}, \mathrm{~F}\right\rangle$ & Characterized as a 5 tuple state: \\
\hline S is the set of states $\left.\mathrm{A}, \mathrm{T}, \mathrm{S}_{0}, \mathrm{~F}\right\rangle$ \\
\hline A is the alphabet & $\mathrm{S}$ is the set of states \\
\hline T is the transition function: & A is the alphabet \\
\hline $\mathrm{S} \times \mathrm{A} \rightarrow \mathrm{S}$ & T is the transition function: \\
\hline So is the initial state & S $x(\mathrm{~A} U\{\varepsilon\}) \rightarrow P S$ \\
\hline F is the set of accepting states. & So is the initial state \\
\hline
\end{tabular}




\section{Alergia Algorithm}

Our main focus is on an algorithm that can encode the strategy for understanding the DNA sequences. This algorithm belongs to the family of functions that can be determined as Stochastic Finite State Transducer (SFST) [16][18]. Stochastic Moore machine is nothing but the probabilistic distribution of symbols.

We will use Alergia algorithm for our DNA recognition which is discussed as follows.

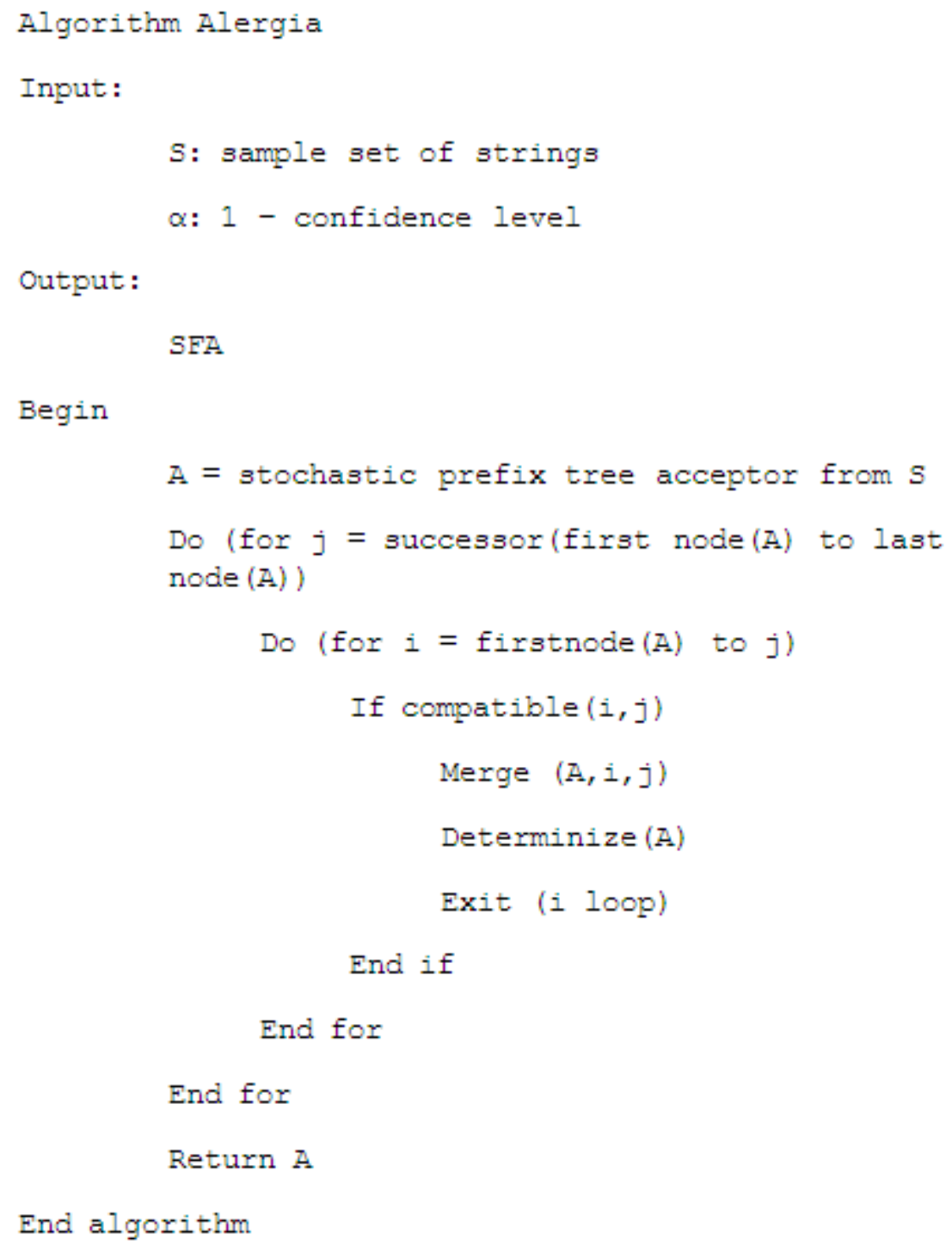


There are 4 major groups of amino acids: Polar, Non polar, positively charged and negatively charged. To build automata we have to convert these to numerical.

Hence, we will enumerate them in the following way:

\section{NonPolar-0}

Glycine (G) - GGU, GGC, GGA, GGG;

Alanine (A) - GCU, GCC, GCA, GCG;

Valine (V) - GUU, GUC, GUA, GUG;

Leucine (L) - CUU, CUC, CUA, CUG, UUA, UUG;

Isoleucine (I) - AUU, AUC, AUA;

Proline (P) - CCU, CCC, CCA, CCG;

Methionine (M) - AUG;

Phenylalanine (F) - UUU, UUC;

Tryptophan (W) - UGG

Polar-1

Serine (S) - UCU, UCC, UCA, UCG;

Threonine $(T)$ - ACU, ACC, ACA, ACG;

Cysteine (C) - UGU, UGC;

Asparagine (N) - GAU, GAC;

Glutamine (Q) - CAA, CAG; 
Tyrosine (Y) - UAU, UAC

Polar Acidic-2

Aspartic Acid (D) - GAU, GAC;

Glutamic Acid (E) - GAA, GAG

\section{Polar Basic-3}

Lysine (K) - AAA, AAG;

Arginine (R) - CGU, CHC, CGA, CGG, AGA, AGG;

Histidine $(\mathrm{H})$ - CAU, CAC

Figure 3 shows that UAA, UAG and UGA are stop codons. We will group them in the final stage as 4.

\section{Stop Codons-4}

UAA, UAG，

UGA 


\section{Creating SFA using Algorithm Alergia}

Let us assume there are ' $n$ ' strings, $S=\left\{s_{0}, s_{1}, s_{2}, s_{3}, \ldots s_{n}\right\}$ and $s_{i}=a_{1} a_{2} a_{3} \ldots a_{i}$.

Once the SFA is build, we start merging the states [16]. Two states can be merged when they are compatible i.e. they have equal transition probabilities for every input a $\in \mathrm{A}$ and the end nodes must be same as well.

$$
\mathrm{q}_{\mathrm{i}} \equiv \mathrm{q}_{\mathrm{j}} \Rightarrow \forall \mathrm{a} \in \mathrm{A} \text {, where } \mathrm{p}_{\mathrm{i}}(\mathrm{a})=\mathrm{p}_{\mathrm{j}}(\mathrm{a}) \text { and } \delta_{\mathrm{i}}(\mathrm{a}) \equiv \delta_{\mathrm{j}}(\mathrm{a})
$$

It's very difficult to find equal frequencies hence states are accepted to be same if they fall under a confidence range.

Given the probability $\mathrm{p}$ and frequency $\mathrm{n}$ for $\mathrm{n}$ values, a confidence range can be defined as:

$$
\left|p-\frac{f}{n}\right|<\sqrt{\frac{1}{2 n} \log \frac{2}{\alpha}} \text { with probability larger than }(1-a) \text {. }
$$

The probabilities are calculated and these values of vital importance for the process of merging. Algorithm Alergia will reject the states if these values are greater than the confidence range.

$$
\left|\frac{f}{n}-\frac{f^{\prime}}{n^{\prime}}\right|>\sqrt{\frac{1}{2} \log \frac{2}{\alpha}}\left(\frac{1}{\sqrt{n}}+\frac{1}{\sqrt{n^{\prime}}}\right)
$$

The above equation helps in merging the compatible states. After merging all the compatible states, we get a SFA [16] which is an estimate of the initial one. 
A DNA nucleotide sequence can be represented in the form of numerical depending on the 4 groups of amino acids discussed in Chapter 4 as follows:

Sequence 1: AUG AGA CCA GCG AGG ACA CCU GAU GAA UGA Input 1: $\quad \begin{array}{lllllllllll}0 & 3 & 0 & 0 & 3 & 1 & 0 & 2 & 2 & 4\end{array}$ Sequence 2: AUG CUC CAU CAA UGG GAC AAA UUU UUC UGG $\begin{array}{lllllllllll}\text { Input 2: } & 0 & 0 & 3 & 1 & 0 & 2 & 3 & 0 & 0 & 0\end{array}$ Sequence 3: AUG AUC ACC UGU GAU AAG GUU AUU CCU CAU $\begin{array}{lllllllllll}\text { Input 3: } & 0 & 1 & 1 & 1 & 2 & 3 & 0 & 0 & 0 & 3\end{array}$ Sequence 4: AUG UCU GAG GAC GAA CGU UCU UGG GAU AAA Input 4: $\quad \begin{array}{lllllllllll}0 & 1 & 2 & 2 & 2 & 3 & 1 & 1 & 2 & 3\end{array}$ Sequence 5: AUG CCU CAU GAU AAG AUC UGU CAU GUU ACC $\begin{array}{lllllllllll}\text { Input 5: } & 0 & 0 & 3 & 1 & 3 & 1 & 1 & 3 & 0 & 1\end{array}$ Sequence 6: AUG AUU CCC UAU GAU GAG AAG GAC AAA UCU $\begin{array}{lllllllllll}\text { Input 6: } & 0 & 0 & 0 & 1 & 2 & 2 & 3 & 2 & 3 & 1\end{array}$ Sequence 7: AUG CAU UAU GAU CAU GAC AAA CCU AUC GAU

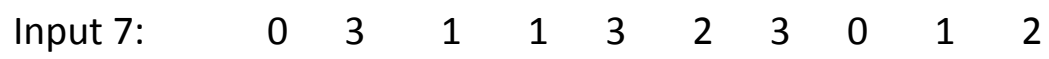
Sequence 8: AUG CCU GAU AUU UGU CAU GUU GAG UAU ACC

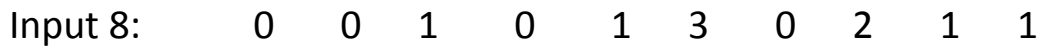
Sequence 9: AUG GAU AAG GAA AAA UCA GAC CUU CCC CAU $\begin{array}{lllllllllll}\text { Input 9: } & 0 & 1 & 3 & 2 & 3 & 1 & 1 & 0 & 0 & 3\end{array}$ 


\section{Sequence 10: AUG AAA AAG GAU UGU CAA GAU AUC GAG CAC}

$\begin{array}{lllllllllll}\text { Input 10: } & 0 & 3 & 3 & 2 & 1 & 1 & 2 & 0 & 2 & 3\end{array}$

Above are a few examples of DNA sequences being represented numerically. Once this is done we can now use Algorithm Alergia to build a prefix tree acceptor (PTA) [3][16]. The algorithm then merges all the compatible states in PTA and creates stochastic finite automata [16][17][18]. This automaton is an estimate of the initial one. 


\section{DNA samples of living organisms}

There are approximately 8.7 million species of species on our planet out of which 6.5 million are from land and the remaining from the seas [8].

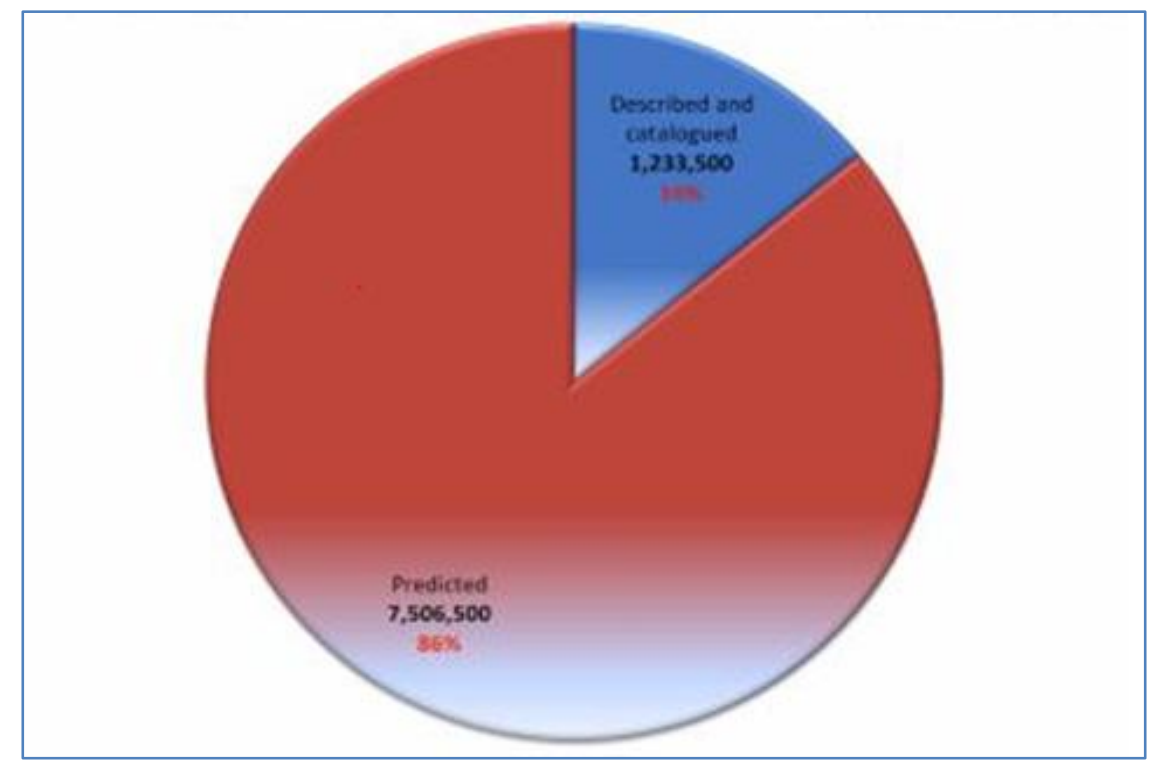

Figure 4: Total Number of Species on Earth [8]

As shown in the above figure, only 1.8 million species have been categorized and known to mankind. This clearly states that around $75-90 \%$ of them are yet to be discovered.

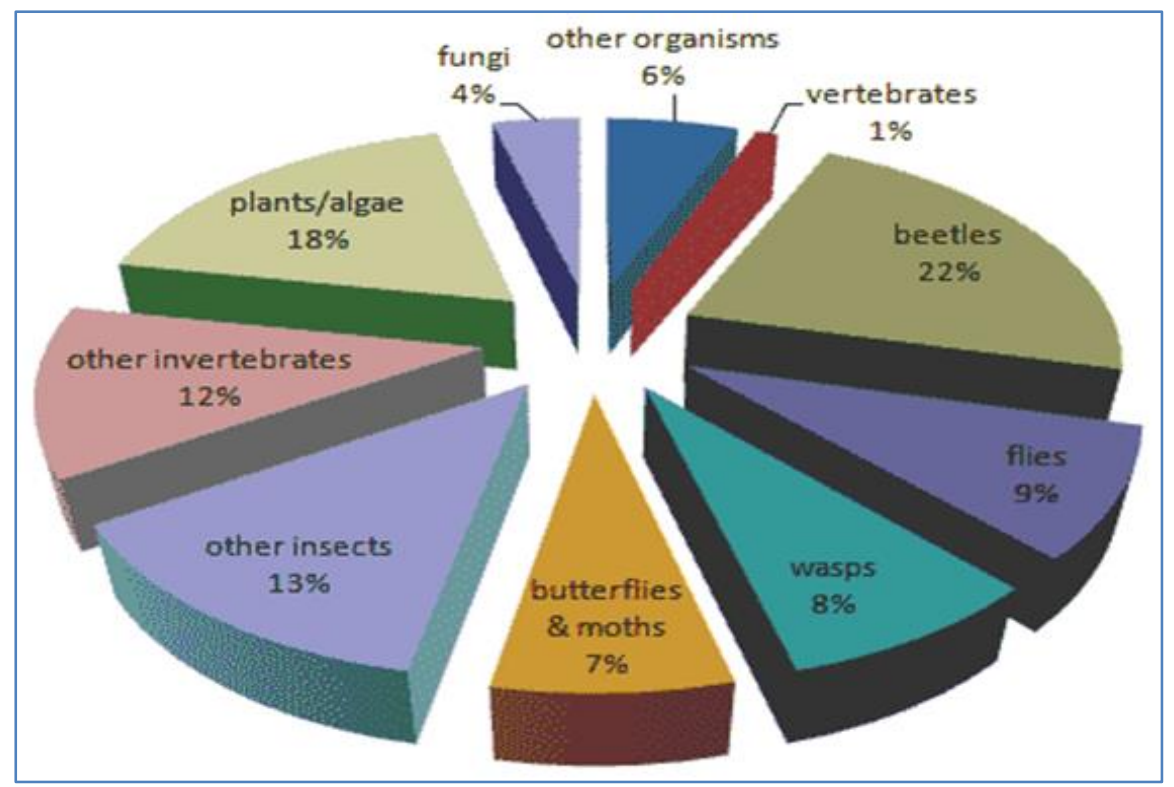

Figure 5: Relative Number of Named Species [7] 
The above chart shows that there are approximately $12 \%$ of invertebrates such as arthropod, mollusk, annelid, coelenterate etc. Vertebrates, categorized by the existence of spinal cord, include mammals (human beings), birds, reptiles, amphibians etc. Our percentage is the lowest amongst all [7].

Our goal is to find the similarity between different species. Below are samples of DNA sequences [15][19] of some species:

DNA nucleotide sequence for Homo sapiens (Human) [19]:

\begin{tabular}{|c|c|c|c|c|c|c|}
\hline 1 & atttccagct & ttctatgcat & $\operatorname{tctgg}$ & gcta & $\operatorname{gag}$ & gaca \\
\hline 61 & gagagaaaga & tttaggcact & ggctttgaa & atagaaagca & cctcaaatgc & tggggagaag \\
\hline 121 & gaacacacag & aaatagcaa & aaaggatcc & agtgagacct & gggcaatgca & caaatgcaat \\
\hline 181 & gcaccacttt & gagacaatca & gcttcaatt & tacacaagca & gtaacaatgc & tccaaaccac \\
\hline 241 & accetgcagc & tgtcccatgc & accatcaggg & aaatctctga & tgctgctggt & gecetgccag \\
\hline 301 & caccactacc & cactgctgca & tctaactgct & gactgcagtc & attgecccat & cctcactccc \\
\hline 361 & atggattctg & cctgtaacct & gctcttggaa & tctctgact & ctaaagtcta & gegtttatgg \\
\hline 421 & aatactacac & agccacacaa & aataatgaaa & tcatatctt & tgtaccaaca & tggatgcagg \\
\hline 481 & tgaaggccat & tatccttagt & gaaattaaca & gaaaccaaa & taccgtatgt & tctcacttat \\
\hline 541 & aagtgacage & taacactgg & ttactcatgg & acataaaat & aggaacaata & gacactgggg \\
\hline 601 & aatactggag & gggggaagga & gggaaaggaa & caacagttga & aaactaact & gttggttact \\
\hline 661 & atgctcagga & catgggtgac & agtatcattc & ataccccgaa & cttcaatatc & atgtaatgta \\
\hline 721 & ctcatgtaac & aaacctgcac & atgtaccecc & tgaatctaaa & ataagttgaa & attacaaaa \\
\hline 781 & acaaaaata & aaataaaca & aagtttaggg & tgctaagtga & tggcagccag & ggtgtgttta \\
\hline 841 & tacatcagct & gcaagaaatg & ccagaaaagg & gaatatctgg & cattttagc & tgtcgtatca \\
\hline 901 & agaggcaaga & tccacctcat & taaatattag & gtgggaattc & ccaaacacg & gggagaagat \\
\hline 961 & gatgatgttg & tgtagaaaaa & aaaaaaaa & gtaagagcca & ttcactccac & acacaaatgc \\
\hline 1021 & ataaacatt & tagaattggg & ccgggcgcag & tggctcacgc & ctgtaatccc & agcacttggg \\
\hline 1081 & gaggecgaga & cgggcagatc & atgaggtcag & gagatcgagg & tcatcctggc & taacacagtg \\
\hline 1141 & aaatcccgtc & tctactaaa & atacaaaaa & atagccaggt & gtggtggcgg & gegectgtag \\
\hline 1201 & tcccagctac & ttaggaggct & gaggcaggag & aatggcatga & acccaggagg & cggagcttgc \\
\hline 1261 & agtgagcaga & gatcatgcca & ctgcactcca & gcctaggcga & cagtgagact & ccacctcaaa \\
\hline 1321 & aaaaaatcc & atttagaatt & aatatgaaat & tgccatcaga & aattacctct & ggggagtgga \\
\hline 1381 & accagagcta & tagtttcagg & agtgggtgag & agaagattct & tactetcat & tttatatgtt \\
\hline 1441 & tcggtagtat & ttaagaatt & tataagcgac & atatgttet & tetttgatt & tcaaagaact \\
\hline 1501 & ggtttactt & ttaagacctg & tctettct & tagaactgct & tttaaaaaga & ggctggaacg \\
\hline 1561 & tttaattaa & attatgtacc & ctctgcttc & aggaagggag & gccactcaga & tttggtggcg \\
\hline 1621 & gtggttacca & ttcattttt & cattcatta & tcaaagattt & attgattgta & tgcaaggccc \\
\hline 1681 & aagaaagatg & aaagacagag & getctgttet & caaggaggga & attaatgtta & tgatgagaaa \\
\hline 1741 & tgtctttgaa & tgtcttgggt & tttgtgttat & tttctacat & attggtgaac & ctttactc \\
\hline 1801 & agatagtaag & taccetctac & tatacagett & taactagatt & tacttacgtt & tetccetatt \\
\hline 1861 & aaatggaatt & aggaaatata & agttgtacat & cttcacaatg & atttccaagc & taaatgatgt \\
\hline 1921 & tggtggggtc & tttgaaatga & gttactgtgg & aagtattta & tgctcttgaa & cttctgtgga \\
\hline 1981 & agtatttat & getcttgaat & ttcattcaag & aattcaatt & aactcatt & aagattca \\
\hline 2041 & ttagaattag & gtgacatcac & cttatgttt & gtgttggttt & gcaaaagact & tattgctagc \\
\hline 2101 & cagatgtgct & cctttgctg & atagtaatat & aggcattcta & aaagttctaa & tttctaagcc \\
\hline 2161 & ttggatttaa & tacaaacca & taggtaataa & agatgtataa & aaatctagca & cggagtccgg \\
\hline 2221 & $\operatorname{acgcggtggc}$ & tcatgcctgt & aatcccagca & ctttgggaa & tcgaggtggg & tggatcacct \\
\hline
\end{tabular}

Figure 6: DNA sequence of Human [19] 
DNA nucleotide sequence for Chimpanzee [19]:

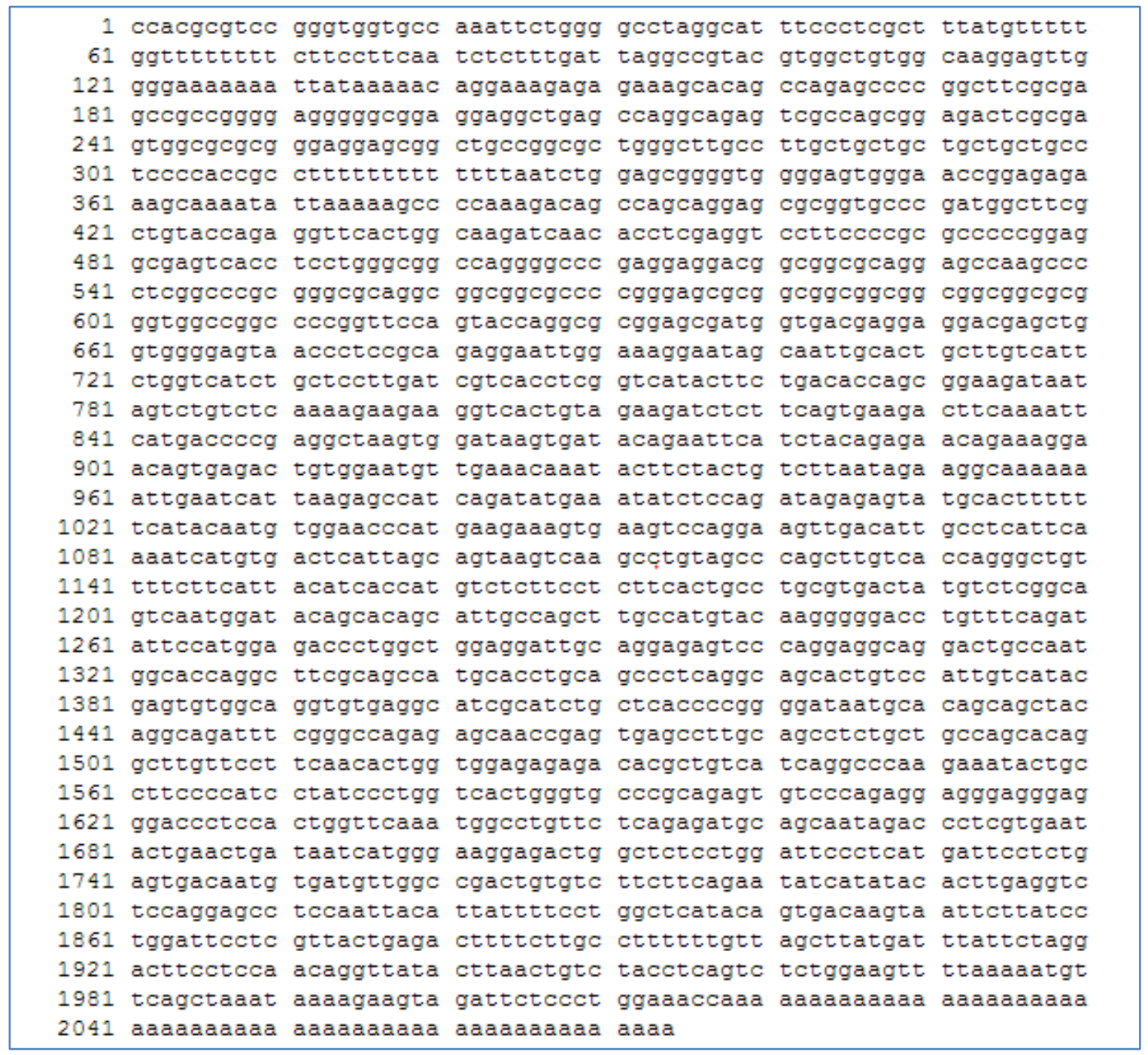

Figure 7: DNA sequence of Chimpanzee [19] 
DNA nucleotide sequence for Monkey [19]:

\begin{tabular}{|c|c|c|c|c|c|c|}
\hline 1 & aagcttctcc & ggcgcaacta & ttctcataat & cgcccacgga & ctcacctcct & ccatgctatt \\
\hline 61 & ctgettagce & aattccaact & atgaacgcac & ccacagtcgt & gttataatgc & tctcccgagg \\
\hline 121 & acttcaagcc & ttacttccac & taatggectt & ttgatgattc & gcagcaaatc & ttaccaatct \\
\hline 181 & agcectaccc & cccactatca & atctaatagc & agagctcett & gttattacag & ctcatttc \\
\hline 241 & ttgatctcat & atcactatca & tactaatagg & gctcaacata & ctaatcacag & ccctctatc \\
\hline 301 & cctctacata & tttatcacaa & cacaacgagg & aaacttaca & caccacacaa & ctaacataaa \\
\hline 361 & gecctcattc & acacgagaaa & acacactaat & attcetcac & cttgecccaa & ttattctet \\
\hline 421 & atccettaac & cctagcatca & tcctaggatt & tacctcttgt & aagtatagtt & taattaaaac \\
\hline 481 & accagattgt & gaatctgact & atagaggcca & gtcacttct & atttaccgag & aaactcgca \\
\hline 541 & aggattgcta & acccatgttc & ccataattaa & aactatggtt & ttctcaact & ttaaaggata \\
\hline 601 & atagctatcc & attggcetta & ggagccaaaa & atattggtgc & aactccaaat & aaagtaaca \\
\hline 661 & attatgtaca & cctccattat & aataacagcc & ctcgtetccc & taattctcc & aatcattgcc \\
\hline 721 & accettatta & accctaataa & aaacagtca & tatccaaact & atgtaaaac & aactacaata \\
\hline 781 & tatgccttca & tcaccagcet & tatcccaata & actctctacc & tctttctaaa & tcaagaggca \\
\hline 841 & actattgaa & gttggcattg & aacaacaacc & caacactaa & atctaacatt & aagctt \\
\hline
\end{tabular}

Figure 8: DNA sequence of Monkey [19]

DNA nucleotide sequence for Mus Musculus (House Mouse)[19]:

\begin{tabular}{|c|c|c|c|c|c|c|}
\hline 1 & ctgggattac & aagctggtac & aactactctg & gaaatcagtt & tggcaggtcc & tcagaaaatt \\
\hline 61 & taatgtaatg & ctacccgagg & acccactaat & accactcctg & gcatctaccc & agaagatgct \\
\hline 121 & ccaatatgta & ataatgacac & atgctctact & atgttcatag & caccettatt & tataataaco \\
\hline 181 & agaagctgga & aagaacccag & atgtccetca & gcagaggaat & ggatacagaa & aatgtggtat \\
\hline 241 & atttatacaa & tggaatacta & ctcagctatt & aaaggagtg & aattcatgaa & attcttaggo \\
\hline 301 & aaatggatgg & aattagaaaa & tatccttagt & gaggttaccc & aatcacaaaa & gaacacacat \\
\hline 361 & ggtatacact & cactgataag & tggatactag & cccagaagtt & cagaataccc & aagatacaat \\
\hline 421 & ttaaagacaa & aatgaagctc & aagaagaagg & aagaccaaag & tatggatact & ttggtcctto \\
\hline 481 & ttagaagggg & aacaaata & cccatgggag & gagttacaga & gacagcgtgt & ggagcagaga \\
\hline 541 & ctgaaggaaa & ggccattgag & agacttcccc & acctagagat & ccatcccata & tacagtcaco \\
\hline 601 & aaacccagac & agtattgtgg & atgccaacca & gtgettctg & acaggagcct & gatatagcto \\
\hline 661 & tctccttgag & aggctcttgc & cagtgcctga & caaatacaga & gatggatgct & ctctctgago \\
\hline 721 & acaaggcctc & cagtggagaa & gctagagaaa & ggaccaaagg & agctgaagga & gettgcagco \\
\hline 781 & ccataggagg & aacaacaata & tgaaccaacc & agtacctcca & gagctcccag & ggagtaaaco \\
\hline 841 & accaaccaga & gagtatgcat & ggtgggactc & atgactccag & ctgcacatgt & agcagaggat \\
\hline 901 & ggtcttattg & gacatcaatg & ggaggagagg & cgettggtcc & tgagaagact & taatgtccca \\
\hline 961 & gtataggaaa & atgccaggac & agggaagcgt & $g g g t g g g t g g$ & gtggtgagca & $g g g g g t t g g g$ \\
\hline 1021 & ggagagaata & gggggtttc & agaggggaaa & ccaggaaagg & ggattacatt & tgaaatgtaa \\
\hline 1081 & ataaagagaa & aatctaata & aaaaacatt & atgttacaat & aaaaaaatg & agagaaatta \\
\hline 1141 & gtaaagagcc & aatgtttaa & gtggaggtat & tgaataccaa & taatactatg & ttcagatto \\
\hline 1201 & tgaagaactg & ccagaatgat & ttctagaggg & gttataccag & cttgcaatcc & catgaaggag \\
\hline 1261 & tettctct & tcaccacatc & cttgccagca & cctgetgtca & cctgagttt & tgatcttago \\
\hline 1321 & cattctgatt & ggtgagaggt & ggaatctcag & ggcegttttg & attggectt & ctctgatgao \\
\hline 1381 & tgaggatatt & ttctattcca & tgatcttatt & caggattcta & cattgtagtt & agtccttata \\
\hline 1441 & tctcctata & tattcttta & ttaattgatc & attttaatt & tacatttcaa & atgttattco \\
\hline 1501 & ccettcceca & teccectetg & caatccecc & ctatctcact & cctgcacte & tatgagggto \\
\hline 1561 & ctccectacc & cactcattca & ctcctgecte & actgccetag & cattccetta & cgetggggca \\
\hline 1621 & tcgagcettc & acagggccaa & gggectcctc & tcccattaat & gccagataag & gccatcctct \\
\hline 1681 & gctacatatg & gagctagacc & catggatcct & tccatgtgta & ttcttggtt & ggtgttttt \\
\hline 1741 & tettettt & ttttagtcc & ctgggagcac & tgggcaatct & ggctggttga & tactgtttt \\
\hline 1801 & cttcctatgg & ggttgaaaac & ttcttcaact & ccttagtcct & tcccetaact & cttccattgo \\
\hline
\end{tabular}


DNA nucleotide sequence for Banana [19]:

\begin{tabular}{|c|c|c|c|c|c|c|}
\hline 1 & tggatttaaa & getggtgtta & aagattacaa & attgacttat & tatactcctg & actacgaagt \\
\hline 61 & caaagatact & gatatcttgg & cagcattccg & agtaactcct & caacctggag & ttccgcccga \\
\hline 121 & agaagcaggg & getgcggtag & ctgccgaatc & ttctactggt & acatggacaa & ctgtgtggac \\
\hline 181 & tgatggact & accagtcttg & atcgttacaa & agggcgatgc & taccacatcg & $\operatorname{aggccgttgt}$ \\
\hline 241 & tggggaggaa & aatcaatata & ttgcttatgt & agctatcct & ttagacctt & ttgaagaagg \\
\hline 301 & ttctgttact & aacatgttta & cttccattgt & gggtaatgta & tttggttca & aagcettacg \\
\hline 361 & agctctacgt & ctggaggatc & tgcgaattcc & cacticttat & tccaaaact & tccaaggccc \\
\hline 421 & gectcacgge & attcaggttg & aagagataa & gttgaacaag & tatggtcgtc & ccctattggg \\
\hline 481 & atgtactatt & aaccaaaat & tgggattatc & tgcaaaaac & tacggtagag & cggtttatga \\
\hline 541 & atgtctacgt & ggtggacttg & atttaccaa & agatgatgaa & aacgtgaact & cacagccatt \\
\hline 601 & tatgcgttgg & agag & & & & \\
\hline
\end{tabular}

Figure 10: DNA sequence of Banana [19]

DNA nucleotide sequence for Weed [19]:

\begin{tabular}{|c|c|c|c|c|c|c|}
\hline 1 & attgca & $\operatorname{tggctgttcg}$ & ccatttcget & ccatc & cat & att \\
\hline 61 & actaatatta & ataatcattt & ttttggtaga & gaaatttta & caccaaaac & atctaatatt \\
\hline 121 & acaacaaaaa & aatcaagatc & aagacctaat & tgcaatccaa & tccaatgtag & tttggccaaa \\
\hline 181 & agccetagta & gtgatactag & tacaattgtt & lagatcag & ccaactatga & ccatt \\
\hline 241 & tggtctttg & attccattca & gtctcttcca & tgcaaatata & agggagaacc & ctatacaagt \\
\hline 301 & cgatcgaata & agctaaaaga & agaagtgaaa & aagatgttag & ttggaatgga & aactctta \\
\hline 361 & gtccaacttg & agttgattga & tacattacaa & agacttggaa & tatcttatca & ttttgagaat \\
\hline 421 & gaaatcatt & ctattttgaa & agaatattcc & actaatatta & gtactaataa & aaccctaaa \\
\hline 481 & tatgatttat & atgccactgc & tctcgaattt & aggctttac & gcgaatatgg & atatgcaata \\
\hline 541 & cctcaagaaa & tatttaatga & ttttaaggac & gagacgggaa & agttcaaagc & gagtattaaa \\
\hline 601 & aatgatgata & ttaagggagt & attggettta & tatgaagctt & cattctatgt & gaaaaatggt \\
\hline 661 & gaaatatt & & gtttc & gaat & atcto & atatgtaatg \\
\hline 721 & atgattgatc & aaacataat & attaaatgat & aatatggcaa & tattagtgag & acatgcettg \\
\hline 781 & gagatgccac & ttcattggag & gactataaga & gcagaagcta & agtggttcat & tgaagaatat \\
\hline 841 & gagaagacac & aagacaagaa & tggcactttg & cttgaattg & cgaaattgga & tttcaacatg \\
\hline 901 & cttcaatcaa & tatttcaaga & agatctaaaa & catgtctcga & ggtggtggga & acattctgag \\
\hline 961 & cttggaaaga & ataaatggt & ttatgctaga & gatagattgg & tagaggett & tctatggcag \\
\hline 1021 & gttggagtaa & gatttgagcc & acaattcagc & cacttagga & gaatatctgc & aagaatatat \\
\hline 1081 & getctaatta & caatcataga & tgacatatat & gatgtgtatg & gaacattgga & agagttagag \\
\hline 1141 & ctttcacca & aggctgttga & gagatgggat & gcgaagacca & tacacgagtt & accagattat \\
\hline 1201 & atgaagttgc & cttcttac & tttattaac & accgtaaatg & aaatggcgta & tgatgtatta \\
\hline 1261 & gaagagcata & atttggtcac & cgttgaatac & ctcaagaact & cgtgggcaga & gttatgtagg \\
\hline 1321 & tgctattgg & aagaggcaaa & atggttctat & agcggataca & aaccaacct & gaaaaatat \\
\hline 1381 & attgagaacg & cctcgetttc & aataggagga & caaattatt & ttgtatatgc & tetetctct \\
\hline 1441 & cttacaaagt & ccataacaaa & cgaggcetta & gagtccttgc & agggtca & tcacgctgca \\
\hline 1501 & tgtcgccaag & gatccttaat & gttacgactt & gcagatgatc & taggaacatt & gtcggatgaa \\
\hline
\end{tabular}

Figure 11: DNA sequence of Weed [19] 
DNA nucleotide sequence for Drosophila Melanogaster (Fruit Fly) [19]:

1 gaattctga atatatccaa gtctagttac gcacctct caccaggcga catttgacaa

61 cattgtcgtt gagcggatgt gtcgtcatat cgaagagtag aaaatttgc ttttccgtcg

121 tgagcacacc cttctccacc agattttgg ccagacgttc gcgtacattt ttcagttggt

181 agcgcaatt caacggattc caggtttcac ctgccacaac aataggttat acaaacata

241 cttggcgaaa tggcaggcgc taaatacaca ccactaagat attcaatcca gctctgcacc

301 gtctccgggg gatctgtttc cttaatgtgt ttaagtccet ccaccactaa gatattcaat

361 ccagctctgc accgtctccg ggggatctgt ttccttaatg tgtttaagtg cctcatcgag

421 tagaacgtct cccgtctget gatccgatt cagtattaat ttcctigtac atagaccacg

481 tcgccgcatt ccagattct cgatcatcac gegacctcge agtccaagct ctatgagaat

541 gcatccgcgc aagccgettg atatgcagtc gttccagaaa gatgtgtagc cetccttgtc

601 cttgagtccc agcagcagaa cctcctccat gagcgttagt cgtgtttcct tggagtcgec

661 atcgtcgata ttgtcctcct ggtctcatac acgcacacaa acacagcgag agcgagatgt

721 ccgagaaaaa cetgaaagtg ggcgcccggg tcgagctgac cggcaaggat ctgcttggca

781 cggttgccta cgtggggatg accagcttcg cgtcggcaag tgggtgggcg tcgtgctgga

841 cgagccgaag ggcaaaaca geggctccat caagggccag cagtacttce agtgcgatga

901 gaactgtggc atgtttgtgc gacccacgca getgcgtctg ctggaggctg ctcctggcag

961 caggcgcagc atcgaggatg tcagcggggc tacgcccacg gctgcecaac ccacaaaggc

1021 gcggetgagc agctctcgca cctcgetctc ctccagtcgc caatcgetgc tgggttcccg

1081 cacccagttg accacttctc tgagtgaacg cactgcctcc agcagcagta ttggcccgag

1141 gaaatctttg gcgccgcaaa acagcaagga taaggagtcc cccagcactt cattggcaga

1201 aggagcccea gcagcaagcg gtggcaacgg tgccgttcgc atgcetcctc caaacggget

1261 tccttcgtgg agacgggett cettgaaat cttaagccgc agttcacgec ttcccagcca

1321 ctgcgatcgc cetcttcac catgccetcc aactccggtg ctgaagacaa ggttcgecct

1381 gctggaggca cagaaaacga gcgccgagct gcaggctcag ctggctgatc tcaccgagaa

1441 gctggaaact ttaaagcagc gcaggaacga ggataaagaa aggttgcggg agttcgacaa

1501 gatgaagatt cagtttgagc agcttcaaga gtttcgaacg aaatcatgg gtgctcaggc

1561 ttcgcttcag aaggagttac tgcgcgccaa acaggaggcc aaggatgcaa tcgaggccaa

1621 ggagcagcat gctcaggaaa tggcagatct ggcagacaat gtggagatga tcacgctgga

1681 caaggaaatg gccgaggaga aggccgacac gctgcagctg gagctagagt cctccaagga

1741 gcgtattgaa gagttggagg tagatctgga getcttacgc tcggagatgc aaaacaaggc

1801 cgaatctgce atcggaaata tttctggegg cggcgattcg cegggectct ctacttatga

1861 attcaaacag ctggagcaac agaacattcg tttgaaggaa acactagtgc gtctgaggga

1921 tctatctgct cacgacaagc acgacatcca aaagttgagc aaggaactgg agatgaagcg

1981 ctctgaagtc accgaactgg agcgcaccaa ggagaagctt agtgccaaga ttgatgaact

2041 ggaggccata gtcgccgact tgcaggaaca agtcgatgct gcacttggtg ccgaggaaat

2101 ggtggagcag ctggctgaaa agaaatgga attggaagac aaagtaaaac tgctcgagga

2161 ggaaattgcc caattggagg cettggagga agtgcacgaa cagctggtgg agagtaacca

2221 cgaactggag cttgatctgc gcgaggaatt ggatctcgcc aatggggcca aaaaggaggt

2281 gctgcgagag cgggatgctg ccattgaaac catctatgat cgcgaccaaa ctatcgttaa

2341 gtttagggaa ctggtacaga agctaaacga ccaactaact gagttaaggg atcgcaattc

2401 tagcaacgaa aaggagtcgt tgcaggatcc cagtttgaaa atggtcaccg aaaccatcga

2461 ctacaacaa atgttcgccg aatccaaggc ttacactcgc gccatcgacg ttcaactgcg

2521 ccagattgag ctgagccagg ccaatgagca tgtccagatg cttaccgcct tcatgcctga

2581 gtcattcatg agtcgcggtg gcgatcacga ctcaatcct gtgattctgc tcatttcacg

2641 cattgtctt aagtgcgcac attgtcgttt cgcaaacgag agagcgtttc ccaccagtgg

Figure 12: DNA sequence of Drosophila Melanogaster [19] 
DNA nucleotide sequence for Oryza sativa (Rice) [19]:

1 tcccaaaca atgtgtctat ggtcttccga attcctagtc tcagcattgt gcaccaccga

61 gctaggttgc agactatcac gatctgcttg atatatagtg tcaatttggt gtgtaccaac

121 taaaggttgg tttgcatta ccgtcttct ttgtttatta gcaattgttt ctcgctgagt

181 ggccatact cttcctctct tttagtgag tggaagttga gtggttttat ttggtacctc

241 cactcttct ggcgcattct gagcgggaat gaaagattta gtcacacct tataattggt

301 aaatgcatct ggcagattat ttgcaagtct ttgcaaatgt ataatttct gaacttgaag

361 ttcagtttca gtagtacgtg ggtctgaggc tggaacacct tgggcatccc aatcaattcc

421 ctggcattct ttctggtact tgaagtctcc ccctaatgcc gggaaatgtt actcatcaaa

481 gatagagtca gcgaaccagg cagtaaatag atcacatgtt aagggttcta aatacttat

541 gatcgacgga gatttgaatc ccacatagat ccccactttc ctgtgtgggc ccatagcagt

601 acgctgtggt ggtgagatcg gtatgtatac aacacaaccg aacttacgca aatgggaaat

661 atttggaaga tttccacgta ctaactgcat tggggaagtt tcatgatatg cagttggtcg

721 tagttggaca aggtcagcag cgtgcagaac tgcatgaccc caacacgacg aaggtaattt

781 gcaattcatc aataatggtc gagtaataag cttaattct tttatcaatg attcagccaa

841 accattttgt gtgtggacat atggaacaaa gtgttgaacc tgaattccca atgccataca

901 ataatcatcg aagcatggg atgtaaatc ggcagcattg tccatacgga ttgattgaat

961 cctatgttca gggtaatttg cctcagcct tataatttga gacattaatt tggcaaaggc

1021 atggtttcgt gtcgatagaa gacacacatg agaccatcta gtagatgcat caatcagaac

1081 cataaagtac ctaaaggtc cagatcttgg cacaataggg ccatagatat ctcctgaat

1141 gcgttcaagg aatttaagtg gttcggctct aattttgaga taagatggtc tcaaaatcag

1201 tttcccagta gcacatgcag tgcatacgaa atcggaggat ttgggaaatt tgtcagtgat

1261 caartgatga ccaatagagt tgccaataat ttttctcatc atcccgatac tagggtgccc

1321 aagtcgatca tgccaagtgt ggaatgcatc aacattttga aaaltactt tgtacgtaac

1381 atgtgcaatg ggcttaatgt atgtatagta caatcccgat gtgagagatg gaatttctc

1441 gcaaatgcat ttgccatatc tgttttgttt ggttaagaga agaaattctt ctcgattatc

1501 catatgggtt tcaatgtgaa acccatttg acggatatct ctataactta gtagggtacg

1561 ggttgaatca agatacaata aagcatcctt gattgtaatt tgtgtaccca ttgggagtgt

1621 aataattget catcctgagc caactatcac agtatcgcgc ccagtgatag tcaaactt

1681 gcctctctc tttttgagag tttgaaagta tttgatctcc ctaagtatag agtttgtggt

1741 accactgtcc acaagacata attcctctcc aatcggagtg atatccttag acatctataa

1801 tgaaagaaga attgcttgat taagaattct ttatccaata tatatacata cataaataa

1861 ttaaacatc agatacatag tatgacgttt acaaatgtta atagtacata ctctaatgac

1921 tagcaagtct tataacctta taatataagg gagtttgtac tcatcgactt attacaacca

1981 ttattgttt aacaactat aggatatcaa tatactgtct caaacacact gagattaaag

2041 cagcttatc tctaagtggg acgcactgag attacagtaa atctccaagt gggtccgttg

2101 agcagtattc gatgagcatg tcatccattg cagaaaatgc agcggtatcc tctgggagaa

2161 gagcgaggtt gttctctggt tcaataggag cctagtgaga acttcaaca tccggtctt

2221 ctttgtaag atgaagtgag ctcaaatct tagttcctca gaagacttt tcgccttag

2281 ggatttctga tacaggagaa caagatgttt ttgggatgtg gcaatctta gtgacatgat

2341 agtcagatcc acacctgttg caatgcetgt tgctattgca acgaggttgt ggtgcettac

2401 cctctctt tccttctat cgaccattgg attggcacct tgttgttatg togegtttc

2461 cagtcagatt cttagggtta ttcgaggaat ttccettgaa tccttaagt gcgatactgt

2521 tggtttagta tcttgtcctc cggaaacata gttgatagag ttttctctat ctttctgct

2581 tcgttggctc ttatcgcaaa atatcaactt ggagcaaatg ttgtgaacag catgattgta 2641 ttctgccaca gtttaaatc ctgtaggcgt aaatgaatcc agccataatt agcetcatgc

Figure 13: DNA sequence of Oryza sativa (Rice) [19] 
DNA nucleotide sequence for Agaricus bisporus(Mushrooms) [19]:

\begin{tabular}{|c|c|c|c|c|c|c|}
\hline 1 & accgacgatg & cattctct & tgtctttgc & caccettget & ctcttagtcg & cttcgg \\
\hline 61 & $\operatorname{tggtgcgccc}$ & getgcgatcc & actctatcga & gactttcgat & ggcgagacta & ctggaaagca \\
\hline 121 & catcatcatg & ctcaaggaag & gagtcaagaa & ggaggatctc & ttcgecaact & tcaaggccaa \\
\hline 181 & ggtcgctgta & tcccatcagt & gggaactgat & caatggctt & gccggtgaat & tcgacgagga \\
\hline 241 & gacactgaac & gagcttcgcg & caaaccccaa & cgttgagagc & attcccgagg & acggcctgat \\
\hline 301 & gcacaccatg & actactcaaa & ccaatgcgcc & atggggcctc & gccogattga & getccactac \\
\hline 361 & aaggctcagt & aaccagaacg & ccgcagctct & gaccttcagc & tacaccttcg & atgcttccgc \\
\hline 421 & cggaagtggc & gttgatatt & tcattgttga & taccggcatt & ctcacaacgc & acagtcaatt \\
\hline 481 & $\operatorname{cggtggtcgt}$ & gcagcttggg & gagagacctt & cggtccetac & gcagaccgtg & atggcaacgg \\
\hline 541 & tcatggtact & catgtcgecg & gtactgctgc & tggaagccaa & ttcggtgttg & ctaaatctgc \\
\hline 601 & caacgtcttc & gccgttaagg & tactcagcga & tgaaggttcc & ggttcgatca & ccgatatcgt \\
\hline 661 & ttccggettg & aactegtcg & gccaaagagc & tgcgtccagt & ggcegaccca & cgattgcatc \\
\hline 721 & catgtctcta & $g g t g g t g g t g$ & cctccagcag & tctggacagt & gcagtagctt & ctctcacgaa \\
\hline 781 & cagtggtgtt & cacgttaccg & tcgetgcegg & aaatgataat & gccaacgecg & cgaatacatc \\
\hline 841 & tcccgetcgt & getcettccg & ccattactgt & cggcgcatct & actaccggcg & $\operatorname{acgctcgtgc}$ \\
\hline 901 & ttcattctcc & aacttggaa & gegttgtcga & catcttcget & cceggecaga & gcgtcatcag \\
\hline 961 & ttcttggatc & ggtagcaaca & ctgataccaa & ctgcatctca & ggaacttcca & tggcaactcc \\
\hline 1021 & ccatattgca & ggactcgtcg & cttacttgat & cagtcttcaa & ggaaacgtga & geccegetge \\
\hline 1081 & catgagcacc & aagatcaagt & ccctcagtt & gaagggtgtc & atcagtggaa & ttccttaagg \\
\hline 1141 & aagccettga & gagttgctga & accgggtgtt & acgaattcg & aagccgcata & ttgaaattg \\
\hline 1201 & gaatgtatca & tcatcattat & tccttgtt & tttaaaatc & aagtcaagga & atatacactt \\
\hline 1261 & tgcaaaaaaa & aaaaaaaaa & & & & \\
\hline
\end{tabular}

Figure 14: DNA sequence of Agaricus bisporus(Mushroom) [19]

DNA nucleotide sequence for Felis Catus (Cat) [19]:

1 ggegggggga ggagggtcta agagagcaga aggaaggttt ccatgggaca ggccetcgec

61 tcaacccggg gatcctggtg cgcctcctcc aaggcggcca cgagggggeg ccgcggccgc

121 gcctgcgaac tcacctgtgc agaagcaggc acgcggetgt tctcagccgg cgggatccag

181 cgggcaggtg tgggttcgag cgcgcagagc ttcctgatt tcggtcccce agcgegggtg

241 tccaggeccg ggggtggggt gactggettg ggggetgagc cectcaggtg gagccatcge

301 actgtgtctc cttgaaacca ggctctgage agagagagaa acagagatgt gtgggegett

361 ctccggetgg gggacgtcet cetgegtgtc actctcagge gggegcagce ggeceggtgt

421 tgaccgccgc gtgggcgccc cgacgggcgg agggagaggg aagacgagcg gtaagcaaat

481 cagtgtggag gggagaagac ggaggagacc tccggcaagg agaggaagga agcggagggg

541 ggaggcggga agaggaggag aagcatcaga cctgaaatcc gaggtgggag gggagctggg

601 ggcagggaga ccgggtgtgt ggggcgggtg gcggggcggg ggtgagtgág aggaggccgt

661 ttgeggectg aaccggggag gecttatgaa atgaggcage ggtgggcgeg gttctcggcg

721 gtagaattcc acgggetgtg gaaattccag ggctgttgct tggattgcet gaagaagacg

781 tgtgtgtcgg gttagggtgg ttgagacagg agtgggtgca gagggttctg gggtgcgggg

841 aggcaagtga ccgtgtgtgt acagtgtgag gctgcattgg ggcggcgtga aagcaagtca

901 cgctaatctg gcgagagaga tcatggtcgg gaacgtactt tttccagag tgaggcatgt

961 gtgttccgcc gaggacctac tgaccctctg tgatttcct caagtatgcg cagttcggct

1021 gegcttgtge tctctcgagg taactggtgt ttaaagcatc aaacgegttt tggtgttttg

1081 ctgtatctt gtttggcttg tcctttagt ttaagagtt tgccccagca tctcagagat

1141 acttgtgaat aatcaccaaa atggcccta tttgtatat ttcgtttact tgttccttc

1201 ttatttgtag tttgtggttc attctagtt tttcttgtgg tttatgtgca agataacta

1261 gagtaacgtt cctgatggag tttggagtgt atttaaatga ttcgagttag ttttccctg

Figure 15: DNA sequence of Felis Catus (Cat) [19] 


\section{Test Results}

Comparison of Human, Chimpanzee and Banana

\begin{tabular}{|l|l|l|l|l|}
\hline & Alpha & Human & Chimp & Banana \\
\hline 1 & 0.10 & 99.981 & 99.949 & 89.933 \\
\hline 2 & 0.20 & 99.979 & 97.816 & 87.154 \\
\hline 3 & 0.30 & 99.978 & 95.342 & 81.706 \\
\hline 4 & 0.40 & 99.975 & 94.721 & 74.585 \\
\hline 5 & 0.50 & 99.972 & 92.808 & 70.633 \\
\hline 6 & 0.60 & 99.971 & 90.368 & 63.707 \\
\hline 7 & 0.70 & 99.965 & 89.886 & 59.961 \\
\hline 8 & 0.80 & 99.962 & 88.386 & 54.822 \\
\hline 9 & 0.90 & 99.955 & 86.371 & 52.666 \\
\hline 10 & 1.00 & 99.951 & 84.731 & 49.595 \\
\hline & & & & \\
\hline & & & & \\
\hline & & & & \\
\hline
\end{tabular}

Table 2: Comparison of Human, Chimpanzee and Banana DNA

The above table shows that the DNA of chimpanzee has $84 \%$ similarity with Human DNA and DNA of banana is $49 \%$ similar to human DNA. 
Comparing Human, Chimpanzee and Mouse

\begin{tabular}{|l|l|l|l|l|}
\hline & Alpha & Human & Chimp & Mouse \\
\hline 1 & 0.10 & 99.981 & 99.949 & 97.933 \\
\hline 2 & 0.20 & 99.979 & 97.816 & 97.154 \\
\hline 3 & 0.30 & 99.978 & 95.342 & 96.706 \\
\hline 4 & 0.40 & 99.975 & 94.721 & 94.585 \\
\hline 5 & 0.50 & 99.972 & 92.808 & 93.633 \\
\hline 6 & 0.60 & 99.971 & 90.368 & 92.707 \\
\hline 7 & 0.70 & 99.965 & 89.886 & 91.961 \\
\hline 8 & 0.80 & 99.962 & 88.386 & 89.822 \\
\hline 9 & 0.90 & 99.955 & 86.371 & 82.666 \\
\hline 10 & 1.00 & 99.951 & 84.731 & 81.595 \\
\hline
\end{tabular}

Table 3: Comparison of Human, Chimpanzee and Mouse DNA

The above table shows that the DNA of chimpanzee has $84 \%$ similarity with Human DNA and DNA of banana is $81 \%$ similar to Mouse DNA. 
Comparing Human, Monkey and Fruit Fly

\begin{tabular}{|l|l|l|l|l|}
\hline & Alpha & Human & Monkey & Fruit Fly \\
\hline 1 & 0.10 & 99.981 & 99.941 & 79.103 \\
\hline 2 & 0.20 & 99.979 & 97.814 & 72.974 \\
\hline 3 & 0.30 & 99.978 & 95.360 & 66.286 \\
\hline 4 & 0.40 & 99.975 & 94.722 & 64.605 \\
\hline 5 & 0.50 & 99.972 & 92.800 & 61.993 \\
\hline 6 & 0.60 & 99.971 & 90.363 & 57.127 \\
\hline 7 & 0.70 & 99.965 & 89.898 & 53.581 \\
\hline 8 & 0.80 & 99.962 & 88.545 & 49.232 \\
\hline 9 & 0.90 & 99.955 & 86.371 & 46.116 \\
\hline 10 & 1.00 & 99.951 & 84.931 & 44.685 \\
\hline
\end{tabular}

Table 4: Comparison of Human, Monkey and Fruit Fly DNA

The above table shows that the DNA of monkey has $84 \%$ similarity with Human DNA and DNA of Fruit Fly is $44 \%$ similar to human DNA. 
Comparing Human, Dog and E. Coli (bacteria)

\begin{tabular}{|l|l|l|l|l|}
\hline & Alpha & Human & Dog & E. Coli \\
\hline 1 & 0.10 & 99.981 & 97.923 & 39.202 \\
\hline 2 & 0.20 & 99.979 & 94.701 & 32.346 \\
\hline 3 & 0.30 & 99.978 & 92.456 & 29.282 \\
\hline 4 & 0.40 & 99.975 & 89.980 & 22.167 \\
\hline 5 & 0.50 & 99.972 & 86.976 & 17.593 \\
\hline 6 & 0.60 & 99.971 & 85.049 & 12.152 \\
\hline 7 & 0.70 & 99.965 & 83.728 & 09.361 \\
\hline 8 & 0.80 & 99.962 & 82.983 & 07.991 \\
\hline 9 & 0.90 & 99.955 & 80.624 & 05.668 \\
\hline 10 & 1.00 & 99.951 & 77.828 & 03.120 \\
\hline & & & & \\
\hline & & & & \\
\hline & & & & \\
\hline
\end{tabular}

Table 5: Comparison of Human, Dog and E. Coli DNA

The above table shows that the DNA of Dog has $77 \%$ similarity with Human DNA and DNA of E. Coli is $3 \%$ similar to human DNA. 
Comparing Human, Mouse and Yeast

\begin{tabular}{|l|l|l|l|l|}
\hline & Alpha & Human & Mouse & Yeast \\
\hline 1 & 0.10 & 99.981 & 99.191 & 58.111 \\
\hline 2 & 0.20 & 99.979 & 97.664 & 52.912 \\
\hline 3 & 0.30 & 99.978 & 95.850 & 49.282 \\
\hline 4 & 0.40 & 99.975 & 94.102 & 46.629 \\
\hline 5 & 0.50 & 99.972 & 92.810 & 41.908 \\
\hline 6 & 0.60 & 99.971 & 90.303 & 37.133 \\
\hline 7 & 0.70 & 99.965 & 89.678 & 34.592 \\
\hline 8 & 0.80 & 99.962 & 88.685 & 31.225 \\
\hline 9 & 0.90 & 99.955 & 87.371 & 29.193 \\
\hline 10 & 1.00 & 99.951 & 86.931 & 27.662 \\
\hline
\end{tabular}

Table 6: Comparison of Human, Mouse and Yeast DNA

The above table shows that the DNA of Mouse has $86 \%$ similarity with Human DNA and DNA of Yeast is $27 \%$ similar to human DNA. 
Comparing Human, Fruit fly and Weed

\begin{tabular}{|l|l|l|l|l|}
\hline & Alpha & Human & Fruit Fly & Weed \\
\hline 1 & 0.10 & 99.981 & 78.717 & 58.125 \\
\hline 2 & 0.20 & 99.979 & 71.285 & 52.936 \\
\hline 3 & 0.30 & 99.978 & 67.453 & 49.222 \\
\hline 4 & 0.40 & 99.975 & 64.636 & 46.695 \\
\hline 5 & 0.50 & 99.972 & 62.125 & 42.901 \\
\hline 6 & 0.60 & 99.971 & 59.984 & 33.198 \\
\hline 7 & 0.70 & 99.965 & 55.920 & 29.598 \\
\hline 8 & 0.80 & 99.962 & 52.615 & 25.233 \\
\hline 9 & 0.90 & 99.955 & 48.331 & 22.180 \\
\hline 10 & 1.00 & 99.951 & 44.231 & 18.690 \\
\hline & & & & \\
\hline & & & & \\
\hline 5 & & & & \\
\hline 5 & & & & \\
\hline
\end{tabular}

Table 7: Comparison of Human, Fruit Fly and Weed DNA

The above table shows that the DNA of Fruit Fly has 44\% similarity with Human DNA and DNA of Weed is $18 \%$ similar to human DNA. 
Comparing Human, Cat and Cow

\begin{tabular}{|c|c|c|c|c|}
\hline & Alpha & Human & Cat & Cow \\
\hline 1 & 0.10 & 99.981 & 98.717 & 97.989 \\
\hline 2 & 0.20 & 99.979 & 98.219 & 96.026 \\
\hline 3 & 0.30 & 99.978 & 95.420 & 94.894 \\
\hline 4 & 0.40 & 99.975 & 93.685 & 92.695 \\
\hline 5 & 0.50 & 99.972 & 91.133 & 89.430 \\
\hline 6 & 0.60 & 99.971 & 89.993 & 88.925 \\
\hline 7 & 0.70 & 99.965 & 88.913 & 86.686 \\
\hline 8 & 0.80 & 99.962 & 86.215 & 82.135 \\
\hline 9 & 0.90 & 99.955 & 85.931 & 79.248 \\
\hline 10 & 1.00 & 99.951 & 84.231 & 76.666 \\
\hline
\end{tabular}

Table 8: Comparison of Human, Cat and Cow DNA

The above table shows that the DNA of Cat has $84 \%$ similarity with Human DNA and DNA of Cow is $76 \%$ similar to human DNA. 
Comparing Human, Dog and Mushroom

\begin{tabular}{|l|l|l|l|l|}
\hline & Alpha & Human & Dog & Mushroom \\
\hline 1 & 0.10 & 99.981 & 97.923 & 89.471 \\
\hline 2 & 0.20 & 99.979 & 94.701 & 82.895 \\
\hline 3 & 0.30 & 99.978 & 92.456 & 79.346 \\
\hline 4 & 0.40 & 99.975 & 89.980 & 77.908 \\
\hline 5 & 0.50 & 99.972 & 86.976 & 69.786 \\
\hline 6 & 0.60 & 99.971 & 82.049 & 66.012 \\
\hline 7 & 0.70 & 99.965 & 78.728 & 61.623 \\
\hline 8 & 0.80 & 99.962 & 76.983 & 54.979 \\
\hline 9 & 0.90 & 99.955 & 75.624 & 49.801 \\
\hline 10 & 1.00 & 99.951 & 77.828 & 42.213 \\
\hline
\end{tabular}

Table 9: Comparison of Human, Dog and Mushroom DNA

The above table shows that the DNA of Dog has $77 \%$ similarity with Human DNA and DNA of Mushroom is $42 \%$ similar to human DNA. 
Comparing Human, Dog and Rice

\begin{tabular}{|l|l|l|l|l|}
\hline & Alpha & Human & Dog & Rice \\
\hline 1 & 0.10 & 99.981 & 97.923 & 58.309 \\
\hline 2 & 0.20 & 99.979 & 94.701 & 46.786 \\
\hline 3 & 0.30 & 99.978 & 92.456 & 41.523 \\
\hline 4 & 0.40 & 99.975 & 89.980 & 37.960 \\
\hline 5 & 0.50 & 99.972 & 86.976 & 33.986 \\
\hline 6 & 0.60 & 99.971 & 82.049 & 29.112 \\
\hline 7 & 0.70 & 99.965 & 78.728 & 25.011 \\
\hline 8 & 0.80 & 99.962 & 76.983 & 22.951 \\
\hline 9 & 0.90 & 99.955 & 75.624 & 18.208 \\
\hline 10 & 1.00 & 99.951 & 74.828 & 15.420 \\
\hline
\end{tabular}

Table 10: Comparison of Human, Dog and Rice DNA

The above table shows that the DNA of Dog has $74 \%$ similarity with Human DNA and DNA of Rice is $15 \%$ similar to human DNA. 
Comparing Human, Cow and E. Coli(bacteria)

\begin{tabular}{|l|l|l|l|l|}
\hline & Alpha & Human & Cow & E. Coli \\
\hline 1 & 0.10 & 99.981 & 97.130 & 39.202 \\
\hline 2 & 0.20 & 99.979 & 94.195 & 32.346 \\
\hline 3 & 0.30 & 99.978 & 92.222 & 29.282 \\
\hline 4 & 0.40 & 99.975 & 89.900 & 22.167 \\
\hline 5 & 0.50 & 99.972 & 86.928 & 17.593 \\
\hline 6 & 0.60 & 99.971 & 82.022 & 12.152 \\
\hline 7 & 0.70 & 99.965 & 81.123 & 09.361 \\
\hline 8 & 0.80 & 99.962 & 79.646 & 07.991 \\
\hline 9 & 0.90 & 99.955 & 77.186 & 05.668 \\
\hline 10 & 1.00 & 99.951 & 76.925 & 03.120 \\
\hline
\end{tabular}

Table 11: Comparison of Human, Cow and E. Coli DNA

The above table shows that the DNA of Cow has $76 \%$ similarity with Human DNA and DNA of E. Coli is 3\% similar to human DNA. 
Following is a table which shows the similarity between different species. For example, the Human and Chimps are $87 \%$ similar (84\% according to our test result), Dog and Mouse are $82 \%$ similar ( $87 \%$ according to our test result). The results below are almost in accordance with the tests we have conducted.

\begin{tabular}{|l|l|l|l|l|l|l|}
\hline Homologs & Human & Chimp & Dog & Mouse & Rat & Fruit Fly \\
\hline Human & -- & $\begin{array}{l}29529 \\
87 \%\end{array}$ & $\begin{array}{l}27761 \\
81 \%\end{array}$ & $\begin{array}{l}26830 \\
79 \%\end{array}$ & $\begin{array}{l}23860 \\
70 \%\end{array}$ & $\begin{array}{l}13276 \\
39 \%\end{array}$ \\
& & $84 \%$ & $77 \%$ & $81 \%$ & $73 \%$ & $44 \%$ \\
\hline Chimp & 18898 & -- & 16865 & 16194 & 14283 & 7673 \\
& $87 \%$ & & $78 \%$ & $75 \%$ & $66 \%$ & $35 \%$ \\
& $84 \%$ & & $71 \%$ & $79 \%$ & $68 \%$ & $38 \%$ \\
& & & & & & \\
& & & & & & \\
\hline Dog & 28144 & 27139 & -- & 26740 & 23816 & 22771 \\
& $82 \%$ & $89 \%$ & & $88 \%$ & $78 \%$ & $75 \%$ \\
& $77 \%$ & $82 \%$ & & $91 \%$ & $74 \%$ & $69 \%$ \\
\hline Mouse & 16384 & 15674 & 16066 & -- & 14067 & 7887 \\
& $83 \%$ & $82 \%$ & $84 \%$ & & $74 \%$ & $41 \%$ \\
& $81 \%$ & $78 \%$ & $87 \%$ & & $76 \%$ & $45 \%$ \\
& & & & & & \\
\hline \multirow{2}{*}{ Rat } & 12409 & 11907 & 12184 & 12420 & -- & 6592 \\
& $70 \%$ & $90 \%$ & $92 \%$ & $94 \%$ & & $50 \%$ \\
& $73 \%$ & $92 \%$ & $89 \%$ & $91 \%$ & & $49 \%$ \\
& & & & & & \\
\hline
\end{tabular}

Table: Homologous gene Summary Chart [21] 


\section{Future Work}

Although 1.8 million species are discovered today, all their DNA nucleotides are not easily accessible to study the differences and the similarities between these organisms. Also, DNA can be represented in 3D structures [12][20] depending on the behavioral patterns of proteins in the amino acids. This can be achieved in future research.

\section{Conclusion}

Pattern recognition of sequential symbolic data using automata theory was proposed in 2005 by Dr. Lin [1] and is being researched since then by him and his students. His student, Nikhil Kalantri has proposed an approach for author identification using the Alergia algorithm for pattern recognition.

In this project, two or more species can be compared on the basis of their DNA genome. The nucleotide sequences help us understand and learn the theory of life and the evolution of living organisms by comparing two species or by comparing the two organisms of the same species. For mathematical results, theory of automata proves to be vital importance. A PTA formed by the use of Alergia helps us understand the DNA genome in a better way. 


\section{References}

1. P.Baliga and T.Y.Lin: Kolmogorov Complexity Based Automata Modeling for Intrusion Detection. Proceeding of the 2005 IEEE International Conference on Granular Computing, " July 25-27, Beijing, China (2005)

2. Pevsner, J. \& Wiley, J.: Bioinformatics and Functional Genomics. (2003)

3. M.Young-Lai and F.Tompa: Stochastic Grammatical Inference of Text Database Structure. Machine Learning (2000)

4. Bosnacki D., Eikelder H.M.M., Steijaert M., Vink E.: Stochastic Analysis of Amino Acid Substitution in Protein Synthesis. In: CMSB 2008, LNBI 5307, 367-386, Springer-Verlag Berlin Heidelberg (2008)

5. Cotter, N., Gesteland, R., \& Murdock, M.: Neural network based pattern recognition for sequenced DNA autoradiograms. In: International Joint Conference on Neural Networks, 2, 909 (1991)

6. Burks C., Farmer D.: Towards Modeling DNA Sequences as Automata. In: Physica D: Nonlinear Phenomena, Volume 10, 157-167 (1984)

7. Information about existing species: http://www.backyardnature.net, [Online - May 2013]

8. Total number of estimated species on Earth: http://www.plosbiology.org, [Online June 2013]

9. Martin, J. C. \& Hawk, J. F.: DNA sequence analysis by optical pattern recognition. In: The International Society for Optical Engineering, 938, 238-45(1988) 
10. Anderson C., Brunak S.: Representation of Protein Sequence Information by Amino Acid Subalphabets. In: American Association for Artificial Intelligence, Volume 1, 97104 (2004)

11. Crick F.: The Great Ideas of Today 1980, Encyclopedia Britannica, 644-683(1980)

12. Paul Barry, Michael Moorhouse.: Bioinformatics, Biocomputing and Perl: An Introduction to Bioinformatics Computing Skills and Practice (2004)

13. Pierre Baldi, Soren Brunak.: Bioinformatics: The Machine Learning Approach (Adaptive Computation and Machine Learning)

14. Rajeev Motwani, Jeffrey D. Ullman, John E. Hopcroft.: Introduction to Automata Theory, Languages, And Computation (2003)

15. Jir Poner, Filip Lanka.: Computational Studies of RNA and DNA. Challenges and Advances in Computational Chemestry and Physics (2006)

16. Ferdinand Wagner, Ruedi Schmuki, Thomas Wagner, Peter Wolstenholme.: Modeling Software with Finite State Machines: A Practical Approach (2006)

17. Justin Davis.: Finite State Machine Datapath Design, Optimization, and Implementation (Synthesis Lectures on Digital Circuits and Systems) (2008)

18. David J Corner.: Digital Logic and State Machine Design (The Oxford Series in Electrical and Computer Engineering) (1994)

19. DNA Sequences- http://www.ncbi.nlm.nih.gov/gene, [Online - June 2013]

20. Peter H. Raven, George B. Johnson, Jonathan B. Losos, and Susan R. Singer, Biology (7th edition).

21. Comparison of multiple species- http://eugenes.org/, [Online - May 2013] 
